\title{
CERVANTES Y TURQUÍA
}

\author{
EMILIO SOLA
}

1.

Cervantes (1547-1616) es un escritor castellano cuya vida y obra literaria se desarrolla en los años de máximo enfrentamiento entre la Casa de Austria - los Habsburgos, titulares de las monarquías hispana y austriaca, desde las que controlan amplios territorios italianos, flamencos y alemanes - y la Casa de Osmán - los Otomanos, en su momento de máxima expansión histórica también con Solimán el Magnífico, Selim II y Murat III-, que a su vez controla desde Estambul amplios territorios balcánicos, danubianos y la costa sur mediterránea hasta Marruecos.

A partir de 1558 - momento culminante de la alianza de los Valois franceses y los Otomanos contra los Habsburgos, con una espectacular guerra total en el Mediterráneo a raíz de la derrota francesa en San Quintín- Felipe II inició una política cada vez más integrista/ fundamentalista que le convertía en el Rey Católico por excelencia, con un control de la ortodoxia religiosa que alcanzaba niveles paranoicos en no pocas ocasiones y crueles acciones represivas. En el marco de lo que se conoce como Contrarreforma católica.

Es el tiempo de redacción del Viaje de Turquía, en el que el autor — sea Laguna, Ulloa Pereira u otro "hombre de frontera" - pudo aún expresarse con mayor libertad que Cervantes veinticinco años después, aunque eso mismo iba a significar que permaneciese inédito su texto -información reservada, "literatura de avisos" - hasta el siglo XX; lo que sin duda Cervantes no deseaba para sí, como autor que pretendía vivir de sus textos literarios para el teatro o para la edición en novela, como hoy se dice, novela de la que se le considera creador en su modelo moderno.

Es fundamental - por todo ello y como punto de partida- considerar a Cervantes como escritor profesional para un público hispano en plena época de la llamada Contrarreforma católica filipina. 


\section{2.}

Nápoles, Sicilia, Malta y Túnez pueden verse como el centro vital de esa frontera mediterránea, básicamente Habsburgo-Otomana, pero con los hispanos e italianos por un lado, y los franceses, venecianos y sobre todo turco-berberiscos por otro, casi permanentemente enfrentados. Guerra menor y permanente (Braudel. p.e.), guerra di corsa, en una frontera en la que el tráfico de personas - fuerza motriz de todas aquellas marinas de galeras - y de mercancías, pero sobre todo de trigo, de grano, eran el verdadero protagonista del corso y del comercio que movilizaban cada vez mas dinero; esa revolución de los precios que resaltan todos los economistas e historiadores, y ese hombre económico moderno que de nave en nave - la galera o galeota como una empresa económica moderna- transporta mercancías y cédulas de pago o letras de cambio de aquí para allá.

Ese vaivén de la frontera mediterránea es el protagonista indiscutible de no pocas obras de Cervantes, novelas como La española inglesa o El amante liberal, u obras de teatro. Así, en El amante liberal, una mera enumeración de los personajes principales nos muestra la amplitud del panorama literario evocado por Cervantes, para quien la verosimilitud es clave en su teoría literaria:

- Ricardo, siciliano de Trápani, cautivo de Hasán Bajá, nombre que en ese tiempo designaba al hijo de Barbarroja o al musulmán nuevo o muladí veneciano Hasán Veneciano.

- Mahamut, muladí siciliano de Palermo, gran amigo de Ricardo.

- Leonisa, sicilana de Trapani, cautivada por Yusuf, arráez muladí griego.

- Alí Bajá, que sucedía en el gobierno de Chipre a Hasán Bajá, el nombre turco del muladí calabrés Ochali el Tiñoso del Quijote.

- Mercader Hebreo, amo de Leonisa y que se la vende a los Bajáes Alí y Hasán.

- Un Cadí turco que ha hecho la "residencia" —o investigación habitual cuando hay cambio de gobierno- en Chipre, y que se hace cargo de la cautiva Leonisa para llevársela a Estambul al Gran Señor. 
- Halima, esposa del Cadí, muladí griega de padres cristianos, enamorada del siciliano Ricardo.

Los escenarios de la acción son las islas de Sicilia, Pantelleria, Malta o Chipre, y sobre todo el mar. $Y$ es en ese escenario en donde salta el punto de vista de Cervantes, moderno, objetivo, por encima de integrismos/fundamentalismos de ortodoxias enfrentadas: los tres sicilianos, Mahamut. Ricardo y Leonisa, "temían la insolencia de la gente corsaria, pues jamás la que se da a tales ejercicios, de cualquiera ley o nación que sea, deja de tener un ánimo cruel y una condición insolente" (p.205, edi. Castaglia/Avalle Arce).

La sencilla precisión "de cualquiera ley o nación que sea" es el toque magistral cervantino, su esfuerzo por superponerse a una visión oficial propagandística antiturca que forzada la demonización del infiel turco, y en la que el mundo eclesiástico católico - y protestante - jugó destacado papel (lo reseña Delumeau, p.e.)

3.

Cervantes, recién veinteañero, salió para Italia —al parecer huyendo de la justicia, por primera vez sospechoso - en el momento en que va a culminar el enfrentamiento Habsburgo/Otomano y los cristianos nuevos hispanos - los moriscos - sufrieron la política rigorista de Felipe II; esta actitud del rey hispano-Habsburgo - "Antes prefiero perder mil reinos... que reinar sobre herejes" sería una de sus formulaciones clásicas, y está en la base del contemporáneo problema flamenco que comenzaba también por entonces- provocó una sublevación en las Alpujarras granadinas que había de recibir apoyo de los turco-berberiscos y que precisó de una compleja campaña militar que sometió la rebelión y condenó a los granadinos cristianos nuevos/moriscos sublevados al cautiverio o al exilio/éxodo. La toma de Chipre por los turcos a los venecianos - telón de fondo de El amante liberal- se dio en el contexto de esta guerra de las Alpujarras y propició la formación de una Santa Liga católica que culminaría en la batalla de Lepanto, en la que Cervantes participó como soldado y en la que fue herido. 
Es en ese momento en el que la propaganda anti-turca adquiere tintes más integristas/fundamentalistas, plenos de providencialismo y retórica denigratoria del enemigo infiel, hasta el punto de poder hablarse de una "leyenda negra" hispano-católica sobre el turco-berberisco idéntica en sus lugares comunes - acusación de crueldad y sexualidad exacerbada, p.e.- a la "leyenda negra" sobre los hispanos que, desde Italia a principios del siglo XVI y Alemania a mediados de siglo, se ha ido fijando en su expresión clásica en los Países Bajos e Inglaterra a finales de siglo con toda naturalidad, fruto de un prolongado enfrentamiento bélico de gran virulencia (ver Arnoldson y García Cárcel. p.e.).

La "leyenda negra" sobre los hispanos estaría en la base de uno de los arquetipos literarios que comienza a perfilarse en el momento, el del "don Juan" como valentón machista y promiscuo. La "leyenda negra" sobre los turco-berberiscos estaría en la base de otro arquetipo literario que Cervantes trató con maestría, el de la "cristiana cautiva", cuya culminación literaria sería La Gran Sultana.

\section{4.}

Cervantes no volvería a Castilla hasta 1580, con 33 años recién cumplidos, y después de cinco años (1575-1580) de cautiverio en Argel, el corazón/motor del mundo turco-berberisco por entonces, la Argel clásica de Alí Bajá —el calabrés Ochali-, de Ramadán Bajá —de origen sardo- y de Hasán el veneciano. Todo un símbolo del triunfo/Fortuna de los musulmanes nuevos o muladíes en el mundo turco-Otomano frente al fracaso - confiscación y éxodo/exilio - de los cristianos nuevos o moriscos en el mundo hispano-Habsburgo, uno de los perfiles clásicos de esa frontera mediterránea Habsburgo-Otomana.

El marqués de Mondéjar, virrey de Nápoles, tiene una de las formulaciones más claras sobre la postura oficial hispana ante los cristianos que conocen el otro lado de la frontera, el mundo turco-berberisco por dentro, podríamos decir, como Cervantes mismo a su vuelta del cautiverio argelino de cinco años. Lo escribe en una carta que envía a Felipe II desde Nápoles (AGS, Estado, legajo 1073, doc. 166, de 21 de septiembre de 1577, Cervantes está aún en Argel en ese momento) a propósito del mercader veneciano Aurelio Santa Croce, res- 
catador de cautivos y coordinador y pagador de los espías que el rey de España financia en Estambul, él mismo residente en esa ciudad. E1 virrey Mondéjar, a propósito de Santa Croce, sentencia que de él "fiara yo poco, porque de los que han estado tanto tiempo en tierra de infieles por maravilla hay ninguno que sea cristiano". Para esa visión fundamentalista/integrista de la Monarquía Católica, es dudosa la fidelidad/fiabilidad de un súbdito mal cristiano, y alguien que conoce el mundo turco-musulmán en profundidad —un "hombre de frontera” - se convierte en sospechoso inmediato de mal cristiano, en súbdito sospechoso por ello, que tendrá que manifestar su ortodoxia católica de manera muy explicita si no quiere tener problemas.

5.

Exactamente el caso cervantino, sin duda, y es posible que el marqués de Mondéjar tuviera razón: quien conocía la realidad de la frontera — quien conocía la realidad del "otro" - era posible que hubiera adquirido una perspectiva que le inmunizaba para discursos propagandísticos simplistas, como era la retórica de la ortodoxia católica que la monarquía de Felipe II estaba adoptando en ese momento con rigor. $\mathrm{O}$ - lo que hubiera sido aún peor- se convirtiera en un escéptico ante el discurso confesional de cualquier ortodoxia religiosa.

Eso es precisamente lo que sugiere Cervantes en un texto que pudiera ser leído hoy como la constatación de la imposibilidad del debate o polémica religiosa entre cristianos y musulmanes, que aparece en el Quijote y en el que se trasluce la experiencia de la convivencia con los "moros"/musulmanes en Argel. Está en el Quijote, aunque no en el cuerpo principal del libro que en la ficción literaria el autor Cervantes atribuye al segundo autor Cide Hamete Benengeli; arábigo y manchego, morisco por ello - y al que Cervantes no cristianará en la obra como debía ser de rigor en un texto de esa época si no quería levantar sospechas-, Cide Hamete no podía ser el autor de este fragmento, y por ello forma parte de uno de los relatos que se añaden al cuerpo principal, la "Novela del Curioso impertinente" en este caso, novela encontrada en un arcón de la venta en la que se alojaban los protagonistas. A los musulmanes "no se les puede dar a entender el error de su secta con las acotaciones de las Santa Escritura, ni con ra- 
zones que consistan en especulación del entendimiento, ni que vayan fundadas en artículos de fe..."

Hoy parece una afirmación de sentido común, después de los debates sobre los límites de la fe y la razón y el desvinculamiento del discurso científico moderno y contemporáneo del aparato de citas de los libros sagrados de las religiones clásicas, sea la Biblia o el Corán. Algunos cervantistas (Camamis, p.e.) consideran a Cervantes un precursor de los iusnaturalistas del siglo XVII, cuando cree necesario el establecimiento de un derecho/ley natural por encima de las diferentes "leyes" de las religiones clásicas - la ley de Moisés, la ley de Cristo o la ley de Mahoma-, la necesidad, en fin, de una sociedad civil y de un estado laico.

La continuación de la cita parece confirmarlo con rotundidad, y es ahí en donde se puede apreciar la modernidad espléndida cervantina; la polémica religiosa, que siempre se remite a diferentes libros sagrados, es imposible precisamente por no poder hacerse con "ejemplos palpables, fáciles, inteligibles, demostrativos, indubitables, con demostraciones matemáticas que no se pueden negar, como cuando dicen: $<$ Si de dos pares iguales quitamos partes iguales, las que quedan también son iguales $>$... Escrito en el momento clave de lo que en Europa se conoce como "revolución científica", dos decenios antes de que Galileo sentenciara que el libro de la naturaleza está escrito en lenguaje matemático (1623, Il Saggiatore), este fragmento cervantino es emocionante por su agudeza expresiva sin duda.

6.

Descartada la posibilidad de que cristianos y musulmanes -españoles y turcos que integran cristianos nuevos/moriscos y musulmanes nuevos/muladíes, los protagonistas de esa nueva "frontera" que Cervantes conoce y ama- puedan llegar a convencer al otro de "las verdades de mi sacra religión", sólo queda la adopción de una postura fundamentalista/intolerante/belicista o una postura escéptica/tolerante/pacificadora.

Y es esta última la que parece adoptar Cervantes sin ningún tipo de dudas y a pesar de frases o formulaciones concretas - meramente retóricas o secundarias en su expresión literaria-, como puestas 
adrede y hasta resaltadas como defensa ante posibles sospechas que su actitud pueda despertar en un momento de ardor patriótico-católico/ guerrero, antiturco/antimusulmán por el aguzamiento del enfrentamiento Habsburgo/Otomano, azuzado por el mundo clerical católico contrarreformista simbolizado con el alineamiento total de los jesuitas con la política de los Austrias españoles en Europa, en América y en Asia, alineamiento global que se da ya a las claras con Felipe II.

Es en una obra de teatro que se desarrolla en la Berbería, en Orán (Argelia), en donde Cervantes logra una plasmación emblemática de esa postura suya que pudiéramos definir como escéptica/tolerante/ pacificadora, plena de modernidad por ello, de contemporaneidad:

-Tu Mahoma, Alí, te guarde.

-Tu Cristo vaya contigo.

Es en la pieza teatral El gallardo español y son dos galanes soldados, uno cristiano y el otro musulmán, Alí Muzel, en una despedida caballeresca sin igual en la literatura del momento, si no es en las historias atemporales de la literatura caballeresca clásica que culminará con el Ariosto y su Orlando furioso. Pero El gallardo español se desarrolla en un momento histórico bien concreto, el cerco de Orán por el hijo de Barbarroja Hasán Bajá en 1563 — siempre la obsesiva verosimilitud cervantina-, y el soldado español al que alude el título es un soldado Sahavedra que a lo largo de la obra no se sabe bien si va a defender o abandonar la ciudad cristiana amenazada, a pesar de que al final - no hubiera sido viable otra actitud para un público hispano del momento a quien iba dirigida la pieza teatral - vuelve a Orán para defender la ciudad con sus correligionarios y naturales.

7.

Los elementos retóricos circunstanciales de la obra literaria cervantina no pueden ocultar - o despistarnos - la actitud vital e intelectual de ese autor clave de la modernidad hispana y europea en general que es Cervantes, el escritor que sin duda inaugura el arte de narrarse y narrar al otro con más riqueza de enfoques y puntos de vista. El cervantismo internacional sabe ya que Cervantes no era un buen católico-cristiano y sus perfiles críticos erasmistas han sido desmenuzados 
hasta el minimalismo, si se pudiera decir así (Bataillon, Vilanova, p.e.). Las formulaciones retóricas antimusulmanas más o menos agresivas son fácilmente neutralizadas por planteamientos más generales de personajes, situaciones o argumentos cuya glosa puede enseñar más del Cervantes personaje histórico y su opinión que las afirmaciones retóricas en boca de sus personajes literarios.

El personaje del morisco Ricote y su familia es toda una lección cervantina de cómo ser ambiguo y muy claro al mismo tiempo, de habilidad literaria para dejar clara su postura de tolerancia/convivencia/ pacificación.

Ricote, el tendero morisco del pueblo de Sancho Panza y vecino suyo, sinceros amigos ambos, aparece en la segunda parte del Quijote (II, 54) cuando vuelve disfrazado de peregrino extranjero -ya después de la expulsión de los moriscos de 1609- para encontrarse con su familia y llevarla a Augusta (Augsburgo), pensando instalarse allí, pues allí hay "libertad de conciencia". Por boca de Ricote mismo Cervantes va a estructurar los más virulentos discursos inculpatorios de los moriscos y expulsionistas, en ocasiones con tintes retóricos tan acentuados que semejan parodias de lo que sin duda las autoridades de la Monarquía Católica de Felipe III exigía sobre una decisión tan cruel y controvertida, entonces criticada en toda Europa y hasta por el Papa de Roma. Uno de los textos retóricos más extremados lo coloca Cervantes en boca de otro morisco, Jadraque Jarife (Persiles 1, III, c.11):

¡Atropella, rompe, desbarata todo género de inconvenientes y déjanos a España tersa, limpia y desembarazada desta mi mala casta, que tanto la asombra y menoscaba!

Pero lo retórico de las palabras formales de elogio de la expulsión de los cristianos nuevos/moriscos queda desbordado en ambos casos —en el Persiles, con Jadraque Jarife y Rafala, y en el Quijote, con Ricote y su familia - por la acción misma y el perfil de los personajes, sobre todo por la historia de Ana Félix, uno de los personajes femeninos más cautivadores de la literatura cervantina. A pesar de que Ricote se manifiesta abiertamente escéptico — “todavía tengo más de cristiano que de moro, y ruego siempre a Dios que me abra los ojos del entendimiento y me dé a conocer cómo le tengo de servir" - , tanto 
su esposa la Ricota como su hija Ana Félix se sienten ya integradas en la sociedad cristiana y desean quedarse en la que ya consideran su "patria natural", en la que han nacido, con lo que su paso a Argel con un pariente que se siente musulmán -Juan Tiopeyo, "que debe de ser fino moro"- es para ellas destierro/exilio y peligro de desarraigo.

La historia de la cristiana nueva/morisca Ana Félix y de su enamorado el cristiano viejo Gaspar Gregorio, joven mayorazgo, guapo y rico como ella, impregna la trama novelesca del final del Quijote (II, 63-65). Gaspar Gregorio había seguido a su enamorada al destierro de Argel y ambos conseguirán regresar a la "patria natural" donde habían nacido después de múltiples aventuras, simulaciones y travestimientos. Toda la sociedad formal catalana - el Virrey, Antonio Moreno y sus familias y amigos-, Don Quijote y Sancho Panza en Barcelona, se pondrán a disposición de los dos amantes para que puedan permanecer en España, y hasta se diseñaron gestiones en la Corte madrileña, "que en ella, por medio del favor y de las dádivas, muchas cosas dificultosas se acaban".

8.

Lo principal del caso de Ana Félix y Gaspar Gregorio es precisamente el enamoramiento mutuo, el amor que supera las fronteras casticistas, el matrimonio mixto. $\mathrm{Y}$ aquí hay que volver a recordar el perfil cervantino, un autor de novelas y teatro que escribe para un lector/ público natural hispano católico cristiano en los años de la Contrarreforma católica filipina rigorista e inquisitorial. Aunque hoy está claro el perfil del Cervantes erasmista, critico con el sistema y hasta con sospechas de heterodoxia religiosa bastante fundadas (Molho, Márquez Villanueva, Camamis, Eisenberg, p.e.), hay límites difíciles de transgredir si se desea tener "éxito" literario, ser admitido por un público lector hispano de ese tiempo, su público natural.

A pesar de ello la insistencia de Cervantes en mantener los "matrimonios mixtos" - diríamos hoy, aunque matrimonio cristiano al fin por exigencias de público y prudencia de autor profesional- ya es una curiosa novedad sin duda. Ana Felix y Gaspar Gregorio -cristiana nueva/morisca y cristiano viejo- es un matrimonio mixto modélico y pacificador de alguna manera. Pero hay otro ejemplo aún más 
refinado y elaborado, también desarrollado en el Quijote (I, 37 a 42), en la novela corta integrada en él que es la del Capitán Cautivo, Rui Pérez de Viezma, y "la hermosa Mora" Lela Zoraida — "la Mora y el Cautivo"-, otra de las creaciones literarias cervantinas más bellas y refinadas, para algunos (Camamis, p.e.) germen de la novela histórica contemporánea.

Una curiosa inversión totalizadora del arquetipo literario de la cautiva, en donde Lela Zoraida es presentada como hija de Agi Morato, un personaje histórico turco-berberisco de tanta raigambre como Alí Bajá/Ochali o Hasán Veneciano. La hija del Agi Morato histórico, una belleza de la Berbería, se casó con Abdelmelec, heredero marroquí que en los meses en que llegó Cervantes a Argel (1576) preparaba una expedición a $\mathrm{Fez}$ con ayuda turca para recuperar su reino. La expedición fue un éxito y Abdelmelec se instaló en su trono marroquí, pero su esposa quedó en Argel en casa de su padre y con su hijo Ismail, de alguna manera rehén de los turco-berberiscos de Argel. Muerto Abdelmelec en la batalla de los Tres Reyes (1578) —de tanta trascendencia para el momento al morir también el rey Sebastián de Portugal y heredar Felipe II ese reino-, la hija de Agi Morato y viuda de Abdelmelec había de casarse nada menos que con el muladí y rey de Argel Hasán Veneciano, quien utilizó a su hijastro como arma política importante en la región y que no cesó de ascender en la corte Otomana hasta lograr suceder a Alí Bajá/Ochali como almirante de la flota otomana. Una de las más bellas y modélicas biografías de la frontera - como la de su antiguo amo Ochali el calabrés- de un triunfador popular del siglo XVI, la del esclavo que llega a "rey". Puro "príncipe nuevo" de Maquiavelo, el verdadero protagonista de "El Príncipe", inviable en una Europa demasiado señorializada pero viable todavía en esa gran frontera liberadora para tantos que la potencia Otomana propiciaba o sustentaba, uno de los motores más potentes de Europa. La hija de Agi Morato —muladí “esclavón”, esloveno/croata/húngaro/eslavo, o algo así- se había convertido en la esposa del Veneciano, almirante del Gran Señor Otomano, madre a su vez de un heredero de la corona marroquí.

Esas eran las nuevas, las "novellas", las noticias que circulaban por el Mediterráneo todo, de boca en boca — cual circulan hoy todas esas 
historias populares, hasta ese limite posible que denominan prensa del corazón-, y crearían esas mitologías populares que todos conocerían con infinitas variantes y modulaciones. Y que sólo ojos y orejas muy avispadas - las "espías", ojos y orejas del rey- sabían captar y transmitir de manera comprensible, la pura información, abuelos de periodistas, gacetilleros. Las "gacetas de avisos" comienzan por entonces a llamarse a los textos con frecuencia demasiado concisos de estos correveidiles que lo llenaban todo con sus cuentos verdaderos y fabulados a la vez. Lástima que tan pocos supieran escribir con soltura o tuvieran tiempo y dinero para ello. Cervantes, por milagro, fue uno.

¿Qué tiene que ver esta hija de Agi Morato, Lela Zoraida, enamorada de este leonés de las montañas Rui Pérez - hijo de Pero- de Viezma, tan cristiano viejo por tan cerca de la tan mítica Asturias de Covadonga y del tan mítico Santiago? Que tiene un hermano Oidor y un padre que - podría haberlo hecho don Quijote mismo- elabora un discurso sobre cómo medrar en esta vida, lo que significaba "Iglesia o mar o casa real...", en otro de los más admirables pasajes de la literatura cervantina sobre las esencias profundas hispanas.

Y el nexo de unión, Lela Mariem, la Virgen María, a la que Zoraida se encomienda desde niña en Argel, de la que - verdadera obsesión- quiere tomar su nuevo nombre:

Preguntó don Fernando al Cautivo cómo se llamaba la Mora, el cual respondió que Lela Zoraida; y así como esto oyó ella, entendió lo que le habían preguntado al cristiano, y dijo con mucha prisa, llena de congoja y donaire:

- ¡No, no Zoraida: María, María! —dando a entender que se llamaba María y no Zoraida.

Y algo más adelante, se reafirma en ese cambio de nombre, incluso con una expresión coloquial argelina: “- ¡Sí, sí, María: Zoraida macange! —que quiere decir no". María o Lela Mariem es una de las tres mujeres santas por excelencia para los musulmanes, junto a Fátima, la hija del Profeta, y la mujer de Faraón, una de las que se sabe seguro que están en el Paraíso.

Complejidad simbólica - y con la paradójica mente de Cervantes de por medio todo se puede esperar-, en una línea escéptico/ tole- 
rante/pacificadora sin igual en ninguna literatura del momento. Quintaesencia de una heterodoxia que roza la genialidad.

9.

El arquetipo de la Cautiva lo desarrolla plenamente Cervantes en La Gran Sultana, y pienso que es ahí en donde está el nudo del mensaje de Cervantes sobre la frontera Habsburgo-Otomana. Si el Cautivo Rui de Viezma rapta a la belleza de la Berbería -Lela Zoraida/Lela María/ Lela Mariem-, como si de un nuevo "rapto de Europa" se tratara, en La Gran Sultana sucede justo lo contrario. Turquía - esa gran frontera mediterránea que es junto con su dominio colonial berberisco- debería de agradecer a Cervantes que "Europa" pueda comprenderla, amarla como una parte suya. Y si se asumiera su condición fronteriza, admitirla como la parte más bella y creadora. Puro lenguaje mítico/exacto, sintético/literario o que, para esa narración oral que sólo narradores como Cervantes - y Seyyid Murad también- supieron transcribir, su propia historia fronteriza y desarreglada/desregulada.

Cuando Cervantes llegó cautivo a Argel, el otoño de 1576, hacía dos años que Murad III había sucedido a su padre Selim II; su madre era una cautiva veneciana de Corfú que se convertía así en la Sultana Madre, una suerte de Gran Sultana en el Serrallo de Estambul. Sin duda tenía que ser una de esas noticias/avisos de la frontera, de los que traían "los que van y vienen", como se denominaba en ocasiones a los que viajaban entre Estambul y otras ciudades europeas con negocios o correos de avisos, y sobre todo en Argel en los medios del cautiverio, siempre al tanto de la información. Es un modelo plausible para el personaje literario cervantino, que lo elaboraría a su regreso para un público hispano hasta darle una intencionalidad parabólica peculiar al hacer de la sultana veneciana una sultana asturiana, doña Catalina de Oviedo:

En un bajel de diez bancos de Málaga y en invierno, se embarcó para ir a Orán un tal Fulano de Oviedo, hidalgo pero no rico: maldición del siglo nuestro 


$$
\begin{aligned}
& \text { que parece que el ser pobre } \\
& \text { al ser hidalgo es anexo. } \\
& \text { Su mujer y una hija suya, } \\
& \text { niña y hermosa en extremo, } \\
& \text { por convenirles así } \\
& \text { con él también se partieron. }
\end{aligned}
$$

Este podría ser el arranque de la historia de la niña cautiva Catalina de Oviedo, que habría de convertirse en Gran Sultana literaria cervantina paralela a la Gran Sultana real Cali Quartana, veneciana de Corfú.

Cautivada la familia asturiana viajera por el corsario berberisco Morato Arráez, la niña fue vendida en Tetuán a un moro llamado Alí Izquierdo; "la madre murió de pena", y al padre se lo llevaron a Argel. Cuatro años después Morato Arráez vuelve a comprar a la niña Catalina, muy hermosa, y se la lleva a Constantinopla; allí pasará al Serrallo y se enamora de ella el joven sultán. Cómo Catalina de Oviedo se convierte en la Gran Sultana o esposa del sultán Otomano, con el permiso de que siga siendo cristiana - "podrás dar leyes al mundo y guardar la que quisieras”, o algo así (cito de memoria) llega a decirle en un momento el sultán-, así como conservando sus ropas y costumbres hispanas, es el asunto marco de la pieza teatral. Y el resultado es otra de las grandes historias de amor de la literatura cervantina, de final absolutamente feliz. Las últimas palabras que el sultán dedica a su esposa Catalina al final de la representación, así lo indican hasta lo hiperbólico:

$$
\begin{aligned}
& \text { Ven, cristiana de mis ojos } \\
& \text { que te quiero dar de nuevo } \\
& \text { de mi alma los despojos. }
\end{aligned}
$$

En dos ocasiones Catalina de Oviedo había manifestado sus dudas sobre la posibilidad de esa unión; una por la diversidad de "leyes": "pues no junta bien amor / dos que las leyes dividen"; la segunda vez por la diversidad de religiones:

¿Dónde, señor, se habrá visto que asistan dos en el lecho, que el uno tenga en el pecho a Mahoma, el otro a Cristo? 
A pesar de esas dudas, la unión amorosa sale triunfante en la obra, nuevamente la metáfora pacificadora de trasfondo. $Y$ aún se atreve más el autor Cervantes, pues espera que Catalina sea un modelo literario o ejemplo global:

Que de su libertad y su memoria se haga nueva y verdadera historia.

10.

Todo el Quijote puede leerse como una obsesión por la "historia verdadera" - hasta la verdad del "yo sé quien soy" del caballero loco por la lectura que era don Quijote-, con lo que esta alusión final en La Gran Sultana a una "nueva y verdadera historia" puede ser una referencia al propio esfuerzo literario cervantino, autorreferencia o imagen especular. Como ese Cide Hamete, verdadero autor del Quijote frente al falso Avellaneda - "flor de historiadores", "sabio y atento historiador", "puntualísimo escudriñador"-, Cervantes supera la verosimilitud literaria y quiere ayudar a alumbrar la posibilidad misma de narrar una historia de manera diferente, con mayores garantías de veracidad, una historia ya no sólo verosímil sino verdadera. $\mathrm{O}$ al menos posible. $Y$ hasta probable, con lo que se convertiría en una profecía, de esa que gustaba tanto a moros como a cristianos de la época, un modelo para una esperanza. La paz del abrazo amoroso islamocristiano, otro posible "rapto de Europa".

En las dos mujeres - la asturiana Catalina y la turco-berberisca Zoraida/Lela Mariem-, núcleo principal de la parábola global pacificadora que rezuma por estas creaciones literarias cervantinas, hay un momento de duda dramática que alcanza, en los dos casos, tintes casi de tragedia; es el momento de la ruptura con el padre, el hidalgo asturiano y el notable turco-berberisco Agi Morata - este último abandonado en una playa solitaria de la Berbería-, que en ambos casos no bendicen esa unión. Pero la realidad — ¿tal vez sólo ese buen deseo del autor o la formulación de una profecía deseable? - se impone y triunfa la unión amorosa de los esposos.

Ese matrimonio mixto que Cervantes eleva a mito pacificador, de alguna manera, aparece como uno de los perfiles más marcados de esa frontera mediterránea en la que Europa pudiera verse reflejada, y tie- 
ne una bella formulación en un texto excepcional del muladí Seyyid Murad en su biografía de Jeredín Barbarroja de mediados del siglo XVI, de la que se conserva una traducción también excepcional al castellano fechada en 1578 y realizada por el valenciano Juan Luis Alzamora, con la ayuda de un esclavo suyo greco-turco. Es precisamente el texto que abre el gran relato/recitativo, al que se le despojó en la traducción de Alzamora de todos los añadidos retóricos que injuriaban o maldecían a los enemigos cristianos, con lo que el resultado ganó en eficacia evocadora y narrativa.

Cuando sultán Mehemet tomó de los cristianos a Mitiliene, dejó en ella para guarda un buen presidio de soldados. Los cuales, viéndose allí mozos y sin mujeres - y no había moras con quien poder casarse porque en aquella isla eran todos cristianos-, suplicáronle los mandase veer y proveer de manera que ellos pudiesen vivir en su servicio. El Gran Señor, vista su justa petición mandó proveer que pidiesen por mujeres a las hijas de los cristianos. Y no queriéndoselas dar, se las tomasen por fuerza y se casasen con ellas. Y de esta manera habría buena comunicación y contratación entre ellos, y la tierra sería guardada. Los soldados, con esta provisión, quedaron contentos.

La traducción de Alzamora de 1578 permaneció inédita prácticamente hasta el siglo XIX — como tantos textos similares que podrían considerarse como una verdadera "literatura de avisos", de información reservada, sobre el enemigo, sobre el otro-, no se integraron en los circuitos culturales hispanos habituales, y el mundo literario cervantino evocador de esa frontera Habsburgo-Otomana - como una frontera sur de Europa- se quedó como una rareza a medias comprensible a pesar de su "verosimilitud".

Esa "verosimilitud" que hoy nos muestra esa construcción literaria cervantina como más verdadera que la narración europeocéntrica excluyente por ortodoxa y nacionalista - excluyente y belicista - que a lo largo de la modernidad se fue imponiendo, ignorando - si no procurando ocultar o minusvalorar- estos otros relatos más escépticos e irónicos —en el caso cervantino-, integradores y pacificadores. 


\section{BIBLIOGRAFÍA}

De entre la abundante bibliografía cervantina, se pueden escoger algunos trabajos que pueden servir para complementar lo expuesto, a algunos de cuyos títulos se hace referencia en el texto como ejemplo (p.e.).

Bataillon, Marcel, Erasmo y España, México. 1950.

Braudel, Femand, El Mediterráneo y el mundo mediterráneo en la época de Felipe II, México. 1952, 2 vols.

Camamis, George, "El hondo simbolismo de la «hija de Agi Morato»", en Cuadernos Hispanoamericanos, CCC-XIX, 1977, pp. 71-102.

Camamis, G., Benenth the Cloak of Cervantes: The Satanic Prose of «Don Quijote de la Mancha», Nueva York, 1991.

Camamis, G., Estudios sobre el cautiverio en el Siglo de Oro, Madrid, 1977.

Canavaggio, Jean, "Agi Morato entre historia y ficcion", Crítica Hispánica, XI, 1989, pp. 17-22.

Castro, Américo, El pensamiento de Cervantes (1925), Barcelona, 1987.

Eisenberg, Daniel, Estudios cervantinos, Barcelona, 1991.

Garcés, Maria Antonia, Cervantes in Algiers. A Captive's tale, Vandervilt, Univ. Press, 2002.

Márquez Villanueva, Francisco, Personajes y temas del Quijote, Madrid, 1975.

Molho, Mauricio, Cervantes: raices folklóricas, Madrid, 1976.

Oliver Asín, Jaime, "La hija de Agi Morata en la obra de Cervantes", en Boletín de la Real Academia Española, XXVII, 1947-1948. pp. 245-339.

Rossi, Rosa, Tras las huellas de Cervantes. Perfil inédito del autor del Quijote. Madrid, 2000. 
Sola, Emilio y de la Peña, José Francisco, Cervantes y la Berbería, Cervantes, mundo turco-berberisco y servicios secretos en la época de Felipe II, Madrid, 1995.

Sola, E., "Historias de la frontera y oralidad: una cautiva que llega a Gran Sultana". en Las relaciones de sucesos en España (1500-1750), Actas del I coloquio internacional... (junio, 1995), Alcalá, 1996.

Vilanova, Antonio, Erasmo y Cervantes, Barcelona, 1989. 